\title{
Correction to: The Criminalization of Young Children and Overrepresentation of Black Youth in the Juvenile Justice System
}

\author{
Laura S. Abrams ${ }^{1}$ [ $\cdot$ Matthew L. Mizel ${ }^{2}$ Elizabeth S. Barnert ${ }^{3}$ \\ ๑) Springer Science+Business Media, LLC, part of Springer Nature 2021 \\ Correction to: Race and Social Problems \\ https://doi.org/10.1007/s12552-021-09314-7 \\ Publisher's Note Springer Nature remains neutral with regard to \\ jurisdictional claims in published maps and institutional affiliations.
}

The original version of this article unfortunately contained an error. The authors would like to correct the error with this erratum.

The authors made a factual error in identifying the state of Maryland as having a minimum age of 12. As of February 2021, Maryland is one of the 28 states without a minimum age law. Only Utah (with exceptions), California (with exceptions), and Massachusetts have established a minimum age of 12 .

The original article can be found online at https://doi.org/10.1007/ s12552-021-09314-7.

Laura S. Abrams

abrams@luskin.ucla.edu

1 UCLA Luskin School of Public Afairs, University of California, Los Angeles (UCLA), 3250 Public Afairs Building, Los Angeles, CA 90095-1656, USA

2 RAND Corporation, Santa Monica, CA, USA

3 David Geffen School of Medicine, University of California, Los Angeles (UCLA), Los Angeles, USA 